\title{
Challenges of modern medicine-geriatric otolaryngology or the advantages of cooperation between an otolaryngologist and a geriatrician
}

\author{
Anna Skalska', Jacek Składzień \\ 'Department of Internal Medicine and Cerontology, U], Collegium Medicum; Head: Tomasz Grodzicki Ph MD \\ ${ }^{2}$ Department of Otolaryngology U], Collegium Medicum; Head: Jacek Składzień, Ph MD
}

Article history: Received: 30.10.2018 Accepted: 05.11.2018 Published: 06.11.2018

ABSTRACT:

Advanced age is often burdened with many deficits that are a consequence of the aging process, unfavorable lifestyle and multi-morbidity. They contribute to increased morbidity and disability of the older people. Laryngological problems often concern seniors, particularly progressing with age hearing impairment, dizziness, balance disorders, epistaxis, nasopharyngeal diseases, larynx, sinuses, and salivary glands disorders. They are not only a health threat, such as head and neck cancer, but they contribute to the deterioration of mobility, falls and injuries, depression, cognitive functions impairment and, consequently, functional disability, loss of independence and a sense of isolation. In this context, taking as an example the most common ailment, which is hearing impairment, laryngological procedures in the form of the use of hearing aids or cochlear implant improves cognitive functions, mood, self-esteem, opportunities for social interaction and everyday functioning, and the quality of life of older people. In turn, in view of the typical for older age polypathology and of significant reduction of the reserves of the organism, effective treatment aimed at improving health, preventing complications of diagnostics and therapy as well as disability with the desire to maintain independence and good quality of life requires the cooperation of different specialists. The knowledge and experience of geriatricians and the comprehensive geriatric assessment used as the diagnostic tool, aimed at identifying deficits typical of seniors' age may significantly contribute to a more adequate risk and benefit assessment, selection of optimal treatment for a given health situation and identification of high-risk individuals requiring during the treatment period special supervision to reduce the risk of complications and the risk of development of geriatric syndromes such as delirium, cognitive disorders, malnutrition, falls and injuries, functional disability.

KEYWORDS: ageing, ENT problems, hearing impairment, frailty, geriatric preoperative assessment

\section{HEALTH PROBLEMS IN OLD AGE}

The effect of increase in the average life expectancy is a dynamic growth in the percentage of the oldest people over the age of 80 . This age group is characterized with multiple morbidities and the presence of geriatric syndromes, such as mobility disorders, falls, cognitive disorders, depression, incontinence, dizziness, delirium, the coexistence of which limits physiological reserves and regulatory capacity of the system. The consequence of coexistence of chronic diseases and geriatric syndromes overlapping the body's aging process is increasing deficits in the function of many organs and systems that impair the ability to respond to stress factors and maintain homeostasis. The result of the elderly's increased morbidity is the increase in the proportion of geriatric patients in diagnostic and treatment procedures in many medical specialties, and their polypatology and complexity of health problems require a special approach and often cooperation of several specialists.

Health problems in the head and neck cause that the share of older people in otolaryngologic practice also increases [1]. The most frequent causes of complaints to the otolaryngologic counseling center of people aged 65 and over in one year (24.2\%) were ear and hearing disorders [1,2]. This group of causes was also dominant in every age group above 64 , about $43 \%$ of visits in the age group $65-74$, about $32 \%$ in the group $75-84$ and about $23 \%$ of visits over 84 years of age $[1,2]$. Other causes of outpatient visits include epistaxis, imbalance, throat pathologies, injuries, sinus and nasal diseases, diseases of the salivary glands, voice and breathing problems, swallowing difficulties, allergies and craniofacial paralysis [2]. On the other hand, the main causes of elderly people reporting to otolaryngology emergency rooms are imbalance, injuries, ear and hearing disorders, swallowing difficulties, epistaxis, facial nerve dysfunctions, allergic reactions [3].

\section{HEARING IMPAIRMENT AND ITS IMPORTANCE IN THE ELDERLY}

These analyzes indicate that one of the most frequent problems in the scope of laryngological disorders in old age are hearing disorders, with the aging process itself contributing to this by predisposing to receptive hearing disorder. It is estimated that $25 \%$ of people aged $65-75$ and nearly $80 \%$ of people over 75 have hearing loss, and about $10 \%$ of those people have hearing loss so large that 
it exclude the possibility of hearing correction using traditional methods [4]. Similar results were obtained in a British study conducted in a group of over 3900 men [5]. Presence of hearing disorders was found in $27 \%$ of respondents, i.e., almost every 3 men aged 63-85 suffered from hearing loss, which indicates a significant prevalence of this deficit in the geriatric population [5]. Hearing impairment is the cause of impeded contacts, limited social interactions, feelings of isolation and poor quality of life, as well as deterioration of physical functioning in the form of impaired mobility, presence of imbalance, disabilities in everyday functioning [5]. Persons with hearing loss more often suffered from falls, suffer from anxiety or depression [5]. Both assessments conducted as part of the analysis of results of the Health Body Composition Study [6] and the National Health and Nutrition Examination Survey (NHANES) [7] showed an increase in risk of falls in people with hearing loss compared to those with normal hearing. Also, the PolSenior study evaluating the older Polish population indicated that over $40 \%$ of people with profound hearing impairment reported falls, while among those with normal hearing, falls concerned slightly more than $26 \%$ of respondents [8]. The sense of hearing is also important for everyday functioning. Among men with hearing loss assessed prospectively as part of the British Regional Heart Study, the risk of disability in the field of complex daily activities (Instrumental Activities of Daily Living) was more than 2.5 times higher among men with ineffective hearing correction and remained $85 \%$ higher in the group of effective correction by means of hearing aids compared to persons with normal hearing [9]. Furthermore, persons with moderate and severe hearing impairment showed a $63 \%$ higher risk of development of the frailty syndrome compared to persons without a deficit [6].

Moderate and severe hearing impairment also constitutes an important risk factor for worsened cognitive functioning and dementia [10-14]. Compared to people with normal hearing, [12] subjects with mild, moderate and severe hearing impairment had 2-, 3- and 5-fold higher risk of dementia due to various reasons in an over 10-year follow-up period. These observations were confirmed by further research. Twenty-three-year observation of 253 participants of The Atherosclerosis Risk in Communities Neurocognitive Study showed that people with hearing impairment, especially moderate and severe, defined as a hearing disorder above 40 $\mathrm{dB}$ in the speech band at two frequencies, showed deeper cognitive deficits in all assessed neuropsychological tests compared to people with normal hearing. Cognitive impairment was found to be independent of age, sex, education, smoking, diabetes, hypertension, and more severe in people who did not use hearing aids [15]. Similarly, in the 9-year follow-up as part of The Health Body Composition Study conducted among persons with moderate and severe hearing loss, risk of developing dementia was $55 \%$ higher (HR 1.55 95\% CI 1.10-2.19) compared to people with normal hearing [16]. A cross-sectional analysis of the Singapore Longitudinal Ageing Study showed that hearing impairment was associated with more than 3.5 times more frequent dementia (OR 3.63 (1.16-11.4), $\mathrm{p}=0.027$ ), and in prospective observation of persons with initially normal cognitive functions, the risk of mild cognitive impairment or dementia was more than twice as high among people with hearing loss (HR $2.30(1.08$ - 4.92), $\mathrm{p}=0.032$ ) compared to subjects without hearing loss [17].
Connections of hearing disorders and cognitive functions are reflected in imaging studies. Comparison of brain images obtained by magnetic resonance imaging in an average duration of 6.4 years showed a faster reduction in brain volume in its entirety as well as temporal lobe and hippocampus areas in people with hearing impairment compared to persons with normal hearing [18]. Suggested directions for explanation of the relationship between hearing loss and cognitive impairment include the neuropathological or internal cell aging process common for the cochlea and brain, as well as impoverishment and degradation of auditory signals associated with peripheral hearing impairment resulting in volume loss in the temporal lobe associated with sound processing and subsequent effects with respect to semantic memory and cognitive processes dependent on the same regions. However, the opposite direction of changes is not ruled out where primary temporal lobe atrophy may result in a secondary elevation of the hearing threshold [18].

Thus, hearing loss in the elderly should be considered not only in the category of communication difficulties, but in the context of physical and cognitive functioning.

\section{IMPACT OF HEARING REHABILITATION ON THE FUNCTIONING OFELDERLY PEOPLE AND THE ROLE OFAN ENT SPECIALIST IN GERIATRICCARE}

Bearing in mind the main message of contemporary gerontology, which is maintaining or restoring the independence of elderly people and improving their quality of life through prevention and treatment of diseases, minimizing deficits resulting from the aging process, maintaining physical and functional ability, specialized otolaryngologic treatment can make a significant contribution to achieving these goals in persons with hearing disorders. Most studies indicate an improvement in the cognitive function of persons who have had one of the forms of hearing rehabilitation $[4,19,20,21]$. Among people with hearing loss, in comparison to persons who did not use any form of hearing correction, patients using hearing aids and people after cochlear implantation presented a higher level of cognitive functions in neuropsychological tests [19]. Cochlea implantation was conducive to improving the perception of speech in silence and in noise [21]. In people aged 65-80, in whom the period of hearing loss requiring use of hearing aids was on average 17 years; an improvement in perception and understanding of speech was observed after one-sided cochlear implantation from $10 \%$ before implantation to $63 \%$ and $69 \%$ after 6 and 12 months respectively, with a slight improvement in cognitive functions, but a significant improvement in the everyday functioning and maintenance of the patients' independence [20].

Benefits of cochlear implantation also included improving the mood assessed by the Geriatric Depression Scale [19, 20], increasing independence [20], social activity [21], positive impact on self-esteem and quality of life [20,21].

These studies document the way in which modern ENT supports the efforts of geriatricians to maintain the independence of older people and improve their physical and functional fitness, the more 
so that the participation of ENTs is much broader than the problem of hearing deficiency discussed above. Patients are referred to laryngological diagnostics and therapy due to dizziness, one of the more frequent ailments in the elderly, balance disorders, nosebleeds, swallowing difficulties, diseases of the sinus, nasopharynx, larynx; they are also treated for head and neck cancer [22].

\section{THE ROLE OF A GERIATRICIAN IN ENT DIAGNOSIS AND THERAPY}

On the one hand, the assessment of sensory, hearing and balance organs as well as other ENT problems should always be carried out as part of the comprehensive geriatric assessment, as cooperation with an ENT specialist can improve the health and functioning of older patients. On the other hand, treatment of geriatric patients, i.e., persons in an advanced age burdened with chronic diseases, usually in a considerable level of advancement, usually with multi-morbidity and multidrug therapy, with the presence of geriatric syndromes with a high risk of complications and loss of autonomy becomes an increasing challenge of modern medicine. Most often these are persons over 80 , although polypatology may also occur in the period of earlier old age. Advanced age, multi-morbidity, unfavorable lifestyle characterized by a lack of physical activity and improper nutrition, unfavorable ecological and socio-social conditions foster development of the frailty syndrome. Frailty syndrome (in other words weak, frail, fragile, sickly), means a state characterized by reduced reserves and resistance to stressors, resulting from the accumulation of reduced efficiency of various physiological systems and multi-system dysregulation, in which the ability to maintain homeostasis of the body and respond to stressors is significantly reduced. This condition consequently leads to increased susceptibility to the occurrence of adverse consequences, which include hospitalizations, imbalances and falls, functional disability and loss of independence and an increased risk of death [23].

Advanced age is also associated with the occurrence of ENT. According to American data, $47 \%$ of patients with head and neck cancers are people over 64 years of age, and this percentage is expected to continue to increase [24]. The majority of these patients are diagnosed in an advanced stage of the disease, which requires complex surgery, radiotherapy and chemotherapy [25]. And although the effectiveness of older people's therapy is similar to that of younger age groups, the risk of surgery is higher, and the radio- and chemotherapy toxicity is higher as well. The main predictors of worse prognosis and poorer tolerance of such treatment were multi-morbidity and functional limitations occurring in $75 \%$ of people over 70 years of age $[25,26]$.

They also determine the more frequent postoperative complications and increased risk of death [26]. An unfavorable prognostic factor are cognitive disorders that predispose patients to delirium, depression and unfavorable social conditions, especially loneliness, lack of support or help. They increase the risk of adverse events, extend recovery and hospitalization time, contribute to poorer quality of life and increase the risk of death. A systematic review of 31 studies showed that the majority of adverse events and com- plications in treatment of head and neck cancer in elderly patients was associated with existing geriatric problems and deficits [26], which suggests the usefulness of geriatric assessment, which apart from specialist oncological assessment may support the choice of diagnostic and therapeutic methods. Potential complications of diagnoses and therapies carried out in people of advanced age, apart from complications resulting from existing diseases such as acute coronary syndromes, stroke, thromboembolism, pneumonia or other infections, are long-lasting cognitive disorders, delirium, falls and functional deterioration. In surgical patients requiring surgery for various reasons, frequency of the frailty syndrome is estimated at $10 \%$ [27] to $26-28 \%$ [28.29], and this group of patients showed over 2-2.5 times higher risk of non-cancerous postoperative complications $[27,28]$ compared to risk in older people without signs of the frailty syndrome.

Despite the existence of many tools to assess the frailty syndrome, further, simple scales are developed, which take into account parameters of potential significance for patients undergoing surgery, such as age, multi-morbidity index, cognitive function and functional status, neoplastic disease, albumin concentration and nutritional status, risk of delirium $[29,30]$. As all authors emphasize, inclusion of frailty assessment in the estimation of postoperative risk significantly improved the predictive value of scales used to date [27-30]. Modifications of scales for diagnosing frailty are also developed to assess patients with head and neck cancer [31.32]. They focus on assessment of the functional state, deficits of sensory organs and multi-morbidity [31], or multidimensionally, in addition to those mentioned, they also include the assessment of cognitive function and mood, nutritional status, poly-pharmacotherapy or presence of other geriatric syndromes [32]. In the analysis by Adams et al., the frailty index was the strongest predictor of increased mortality and more frequent complications. Mortality increased from $0.2 \%$ in patients with no frailty syndrome to nearly $12 \%$ in the group with the highest value of the frailty index, and the complication rate from $9.5 \%$ to $40.5 \%$ respectively, regardless of age, on the ASA scale (American Society of Anesthesiologists) and classification of wounds [31].

In the face of prolongation of human life, population aging and the increasing number of patients in advanced age requiring diagnostics and treatment, often aggressive, there is a need for a more thorough assessment of geriatric patients in order to balance the risks and benefits, select optimal treatment for a given health situation and identify high risk patients. Identification of high-risk patients is aimed at covering them with special surveillance during the treatment period, focusing on thorough monitoring of health status, risk of complications and risk and developing of geriatric syndromes such as delirium, cognitive disorders, malnutrition, falls and injuries, functional disability. Recognizing the problems of treating patients in older age and the need to improve the quality of care for surgical patients in this age group, the American College of Surgeons National Surgical Quality Improvement Program and the American Geriatrics Society have developed the guidelines for pre-operative assessment of geriatric patients [33]. According to the guidelines of the panel of experts, in addition to classical assessment of the cardiovascular system, respiratory, renal, and hepatic efficiency, optimal pre-operative assessment should include [33]: 
- cognitive functions with particular emphasis on the ability to understand the purpose and extent of planned surgery, patient's decision-making capacity and ability to express surgical informed consent with documentation of the results of assessment in the patient's medical records,

- $\operatorname{mood}$

- risk of delirium, also documented in medical records,

- functional status, mobility, falls in the last year with the patient's possible preparation through rehabilitation and improvement of his physical condition,

- frailty recorded in the documentation,

- nutritional status - with BMI measurement, interview in view of a $10 \%$ decrease in body weight over 6 months, determination of albumin level, and in the case of detection of malnutrition and albumin $<3 \mathrm{~g} / \mathrm{dl}$ - implementation of dietary consultations and nutritional treatment,

- addictions (tobacco, alcohol, drugs) with the prevention of withdrawal syndromes,

- pharmacotherapy for:

- poly-pharmacotherapy with assessment of the possibility of reducing the number of medicines,

- reducing use of drugs that increase the risk of delirium (benzodiazepines, antihistamines, anticholinergics),

- adjustment of dosage of drugs to kidney function,

- use of medicines that reduce risk of cardiological complications, stroke, thromboembolic complications,

- pain control.

It is important to ensure there is time to talk with the patient to explain the plan and purpose of treatment, to know the preferences and expectations of the patient, also discuss possible complications and find out about possible support from family or carers or the need to cooperate with a social worker [33]. It is recommended that decisions regarding planned treatment are based not only on perioperative morbidity and mortality data, but include deficits identified on the basis of comprehensive geriatric assessment and the likely consequences for individual physiological reserves, cognitive consequences of general anesthesia and patient's expectations [34]. Planned proceedings should take into account maintenance of independence, quality of life, return to fitness and functional activity, at least preoperative. Pre-operative assessment should not only be used to make surgical decisions, but also for peri-operative care over older patients. It is important to choose anesthesia techniques to minimize complications, morbidity, cognitive impairment, delirium and mortality. In the case of planned operations, earlier identification of deficits allows for the patient's preparation through rehabilitation, functional improvement and nutritional status. And here, in the process of diagnosing and determining deficits resulting from the aging process, multi-morbidity and geriatric syndro- mes, there is a place for a geriatrician whose tool is comprehensive geriatric assessment (COG). This diagnostic and therapeutic process, including assessment of physical health, mental health, daily functioning and social conditions, allows to determine the patient's deficits and needs.

There are very few studies documenting the benefits of pre-operative geriatric assessment on the post-operative course and treatment outcomes, and their diversity does not allow for meta-analysis [35]; however, it has been reported that its management has reduced the abandonment of treatments from $17.7 \%$ to $5.2 \%$, shorter hospitalization time with an average of 8.9 (7.6) to 4.9 (5.0) days, and postoperative complications were reduced from $8.5 \%$ to $2.3 \%$ [36].

Similarly, benefits were gained by older patients referred to orthopedic surgery subject to "proactive care of older people undergoing surgery" based on COG [37]. Postoperative complications were reduced from $20 \%$ to $4 \%$, delirium from $19 \%$ to $6 \%$, pressure ulcers from $19 \%$ to $4 \%$, delay to mobilization from $28 \%$ to $9 \%$, and hospitalization time decreased from an average of $15.8(13,2)$ up to 11.5 (5.2) days [37].

\section{SUMMARY AND RECOMMENDATIONS}

Prolongation of human life entails new challenges in the form of ensuring the greatest possible safety of diagnosis and therapy of the oldest people, often burdened with multi-morbidity and geriatric syndromes, which significantly limit their functional and cognitive abilities as well as functional reserves of the system. Optimal medical treatment can be ensured by cooperation of specialists in various fields.

Treatment of ENT conditions, improvement of balance and hearing correction contribute not only to improving health, but also to the everyday functioning of the elderly, which helps maintain self-reliance and social relationships and maintain a good quality of life.

In turn, a geriatrician, as a member of the assessment team, qualifying and preparing a geriatric patient for more demanding forms of therapy, such as surgical procedures, conducting a comprehensive geriatric assessment aimed at identifying deficits in various areas of health and functioning, and problems typical of advanced age, may support a detailed and thorough evaluation of the patient, distinguish high-risk patients who require a special approach and supervision, also indicate the directions and methods of pre-operative preparation, which in turn may reduce risk of post-operative complications and improve the prognosis of seniors and long-lived patients.

\section{REFERENCES}

1. Creighton F.X. Jr, Poliashenko S.M., Statham M.M., Abramson P., Johns M.M. 3rd. The growing geriatric otolaryngology patient population: a study of 131,700 new patient encounters. Laryngoscope 2013; 123 (1): 97-102.

2. Özler G.S., Yengil E.: Why do geriatric patients visit otorhinolaryngology? Ear Nose Throat J 2016; 95 (6): 224-229.

3. Dagan E., Wolf M., Migirov L.: Why Do Geriatric Patients Attend Otolaryngology Emergency Rooms? IMAJ 2012; 14: 633-636.

4. Cosetti M.K., Pinkston J.B., Flores J.M., Friedmann D.R., Jones C.B., Roland J.T. Jr, Walczman S.B.: Neurogognitive testing and cochlear implantation: insights into performance in older adults. Clin Interv Aging 2016; 11: 603-613.

5. Liljas A.E.M., Wannamethee S.G., Whincup P.H., Papacosta O., Walters K., Iliffe S., Lennon L.T., Carvalho L.A., Ramsay S.E.: Socio-demographic characteristics, lifestyle factors and burden of morbidity associated with self-reported hearing and vision impairments in older British community-dwelling men: a cross-sectional study. J Public Health 2015; 38 (2): e21-e28. 
6. Kamil R.J., Betz J., Powers B.B., Pratt S., Kritchevsky S., Ayonayon H.N., Harris T.B., Helzner E., Deal J.A., Martin K., Peterson M., Satterfield S., Simonsick E.M., Lin F.R.: for the Health ABC study. J Aging Health 2016; 28 (4): 644-660.

7. Lin F.R., Ferrucci L.: Hearing Loss and Falls Among Older Adults in the United States. Arch Intern Med 2012; 172 (4): 369-371.

8. Skalska A., Wizner B., Piotrowicz K., Klich-Rạczka A., Klimek E., Mossakowska M., Rowiński R., Kozak-Szkopek E., Jóźwiak A., Gąsowski J., Grodzicki T.: The prevalence of falls and their relation to visual and hearing impairments among a nation-wide cohort of older Poles. Exp Gerontol. 2013; 48(2): 140-146.

9. Liljas A.E.M., Wannamethee S.G., Whincup P.H., Papacosta O., Walters K., Iliffe S., Lennon L.T., Carvalho L.A., Ramsay S.E.: Hearing impairment and incident disability and all-cause mortality in older British community-dwelling men. Age Aging 2016; 45: 661-666.

10. Lin F.R.: Hearing loss and cognition among older adults in the United States. J. Gerontol. Series A Biol. Sci. Med. Sci. 2011; 66: 1131-1136. doi: 10.1093/ gerona/glr115.

11. Lin F.R., Ferrucci L., Metter E.J., An Y., Zonderman A.B., and Resnick S.M.: Hearing loss and cognition in the baltimore longitudinal study of aging. Neuropsychology. 2011; 25: 763-770. doi: 10.1037/a0024238.

12. Lin F.R., Metter E.J., O’Brien R.J., Resnick S.M., Zonderman A.B., Ferrucci L.: Hearing loss and incident dementia. Arch. Neurol. 2011; 68: 214-220. doi: 10.1001/archneurol.2010.362.

13. Lin F.R., Yaffe K., Xia J., Xue Q.L., Harris T.B., Purchase-Helzner E. et al.: Hearing loss and cognitive decline among older adults. JAMA Intern. Med. 2013; 173: 293-299. doi: 10.1001/jamainternmed.2013.1868.

14. Fischer M.E., Cruickshanks K.J., Schubert C.R., Pinto A.A., Carlsson C.M., Klein B.E.K., Klein R., Tweed T.S.: Age-Related Sensory Impairment and Risk of Cognitive Impairment. J Am Geriatr Soc 2016; 64 (10): 1981-1987.

15. Deal J.A., Sharrett A.R., Albert M.S., Coresh J., Mosley T.H., Knopman D., Wruck L.M., Lin F.R.: Hearing Impairment and Cognitive Decline: A Pilot Study Conducted Within the Atherosclerosis Risk in Communities Neurocognitive Study Am J Epidemiol. 2015 May 1; 181(9): 680-690. Published online 2015 Apr 4. doi: 10.1093/aje/kwu333.

16. Deal J.A., Betz J., Yaffe K., Harris T., Purchase-Helzner E., Satterfield S., Pratt S., Govil N., Simonsick E.M., Lin F.R.: Health ABC Study Group. Hearing Impairment and Incident Dementia and Cognitive Decline in Older Adults: The Health ABC Study. J Gerontol A Biol Sci Med Sci 2017; 72 (5): 703-709.

17. Heywood R., Gao Q., Nyunt M.S.Z., Feng L., Chong M.S., Lim W.S., Yap P., Lee T.S., Yap K.B., Wee S.L., Ng T.P.: Hearing Loss and Risk of Mild Cognitive Impairment and Dementia: Findings from the Singapore Longitudinal Ageing Study. Dement Geriatr Cogn Disord. 2017; 43 (5-6): 259-268. doi: 10.1159/000464281.

18. Lin F.R., Ferrucci L., An Y., Goh J.O., Doshi J., Metter E.J., Davatzikos C., Kraut M.A., Resnick S.M.: Association of Hearing Impairment with Brain Volume Changes in Older Adults. Neuroimage 2014; 90: 84-92.

19. Castiglione A., Benatti A., Velardita C., Favaro D., Padoan E., Severi D., Pagliaro M., Bovo R., Vallesi A., Gabelli C., Martini A.: Aging, Cognitive Decline and Hearing Loss: Effects of Auditory Rehabilitation and Training with Hearing Aids and Cochlear Implants on Cognitive Function and Depression among Older Adults. Audiol Neurotol 2016; 21 (suppl 1): 21-28.

20. Sonnet M.H., Montaut-Verient B., Niemier J.Y., Hoen M., Ribeyre L., Pariett-Winkler C.: Cognitive Abilities and Qality of Life After Cochlear Implantation in the Elderly. Otol Neurotol 2017; 38: e296-e301.

21. Mosnier I., Bebear J.P., Marx M., Fraysse B., Truy E., Lina-Grande G., Mondain M., Sterkers-Artieres F., Bordure P., Robier A., Godey B., Meyer B., Frachet B., Poncet-Wallet C., Bouccara D., Sterkers O.: Improvement of cognitive function after cochlear implantation in elderly patients. JAMA Otolaryngol Head Neck Surg 2015; 141 (5): 442-450.
22. Składzień J.: Zmiany w narządach laryngologicznych spowodowane starzeniem się organizmu. W: Niemczyk K., Jurkiewicz D., Składzień J., Stankiewicz C., Szyfter W. (red.) Otolarygologia kliniczna. MediPage. Warszawa 2015 tom 2: 867-872.

23. Fried L.P., Tangen C.M., Walston J., Newman A.B., Hirsch C., Gottdiener J., Seeman T., Tracy R., Kop W.J., Burke G., McBurnie M.A.; Cardiovascular Health Study Collaborative Research Group. Frailty in older adults: evidence for a phenotype. J Gerontol A Biol Sci Med Sci. 2001; 56 (3): M146-156.

24. National Cancer Institute. Surveillance, Epidemiology and End Results Program. http://www.ser.cancer.gov. Accessed April 30, 2011.

25. VanderWalde N.A., Fleming M., Weiss J., Chera B.S.: Treatment of Older Patients With Head and Neck Cancer: A Review. The Oncologist 2013; 18: 568-578.

26. Van Deudekom F., Schimberg A.S., Kallenberg M.H., Slingerland M., van der Velden L.A., Mooijaart S.P.: Functional and cognitive impairment, social environment, frailty and adverse health outcomes in older patients with head and neck cancer, a systematic review. Oral Oncology 2017; 64: 27-36.

27. Makary M.A., Segev D.L., Pronovost P.J., Syin D., Bandee-Roche K., Patel P., Takenaga R., Devgan L., Holzmueller Ch.G., Tian J., Fried L.P.: Frailty as a Predictor of Surgical Outcomes in Older People. J Am Coll Surg 2010; 210: 901-908.

28. Revenig L.M., Canter D.J., Taylor M.D., Tai C., Sweeney J.F., Sarmiento J.M., Kooby D.A., Maithel S.K., Master V.A., Ogan K.: Too Frail for Surgery? Initial Results of a Large Multidisciplinary Prospective Study Examining Preoperative Variables Predictive of Poor Surgical Outcomes. J Am Coll Surg 2013; 217: 665-670.

29. Robinson T.N., Wu D.S., Pointer L., Dunn Ch.L., Cleveland J.C., Moss M.: Simple Frailty Score Predicts Post-Operative Complications Across Surgical Specialties. Am J Surg 2013; 206 (4): 544-550.

30. Kim S., Han H.S., Jung H., Kim K., Hwang D.W., Kang S.B., Kim Ch.H.: Multidimensional Frailty Score for Prediction of Postoperative Mortality Risk. JAMA Surg 2014; 149 (7): 633-640.

31. Adams P., Ghanem T., Stachler R., Hall F., Velanovich V., Rubinfeld I.: Frailty as a Predictor of Morbidity and Mortality in Inpatient Head and Neck Surgery. JAMA Otolaryngol Head Neck Surg 2013; 139 (8): 783-789.

32. Kwon M., Kim S.A., Roh J.L., Lee S.W., Kim S.B., Choi S.H., Nam S.Y., Kim S.Y.: An Introduction to a Head and Neck Cancer-Specific Frailty Index and Its Clinical Implications in Elderly Patients: A Prospective Observational Study Focusing on Respiratory and Swallowing Functions. The Oncologist 2016; 21: 1091-1098.

33. Chow W.B., Rosenthal R.A., Merkow R.P., Ko C.Y., Esnaola N.F.: Optimal Preoperative Assessment of the Geriatric Surgical Patient: A Best Practices Guideline from the American College of Surgeons National Surgical Quality Improvement Program and the American Geriatrics Society. J Am Coll Surg 2012; 215: 453-466.

34. Sataloff R.T.: Geriatric surgery in otolaryngology. Ear Nose Throat J. 2018; 97 (3): 50-52.

35. Partridge J.S.L., Harari D., Martin F.C., Dhesi J.K.: The impact of pre-operative comprehensive geriatric assessment on postoperative outcomes in older patients undergoing scheduled surgery: a systematic review. Anaesthesia 2014; 69 (suppl.1): 8-16.

36. Ellis G., Spiers M., Coutts S., Fairbun P., McCracken L.: Preoperative assessment in the elderly: evaluation of a new clinical service. Scottish Med J 2012; 57: $212-216$

37. Harari D., Hopper A., Dhesi J., Babic-Illman G., Lockwood L., Martin F.: Proactive care of older people undergoing surgery ("POPS"): designing, embedding, evaluating and funding a comprehensive geriatric assessment service for older elective surgical patients. Age Ageing 2007; 36: 190-196. 
Word count: 4470 Tables:- Figures: 2 References: 9

Access the article online: $\quad$ DOI: 10.5604/01.3001.0012.7218

Table of content: https://otolaryngologypl.com/issue/11772

Corresponding author: Anna Skalska, Ph Md; Department of Otolaryngology U], Collegium Medicum, ul. Śniadeckich 10, 31-431 Kraków, Polska; Tel.: +48 12 424-89-54; e-mail: anna.skalska@uj.edu.pl

Copyright ( 2019 Polish Society of Otorhinolaryngologists Head and Neck Surgeons. Published by Index Copernicus Sp. z o.o. All rights reserved.

Competing interests: The authors declare that they have no competing interests.

Cite this article as: Skalska A., Składzień ].: Challenges of modern medicine-geriatric otolaryngology or the advantages of cooperation between an otolaryngologist and a geriatrician; Otolaryngol Pol 2019; 73 (1): 1-6 